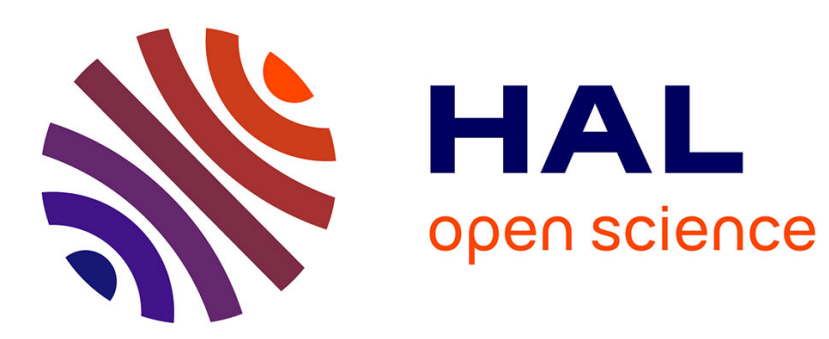

\title{
On the damage criteria and their critical values for flowforming of ELI grade Ti64
}

Dorian Depriester, Elisabeth Massoni

\section{To cite this version:}

Dorian Depriester, Elisabeth Massoni. On the damage criteria and their critical values for flowforming of ELI grade Ti64. MetalForming 2014, Sep 2014, Antibes, France. pp.1221-1227, 10.4028/www.scientific.net/KEM.622-623.1221 . hal-01561767

\section{HAL Id: hal-01561767 \\ https://hal.science/hal-01561767}

Submitted on 13 Jul 2017

HAL is a multi-disciplinary open access archive for the deposit and dissemination of scientific research documents, whether they are published or not. The documents may come from teaching and research institutions in France or abroad, or from public or private research centers.
L'archive ouverte pluridisciplinaire HAL, est destinée au dépôt et à la diffusion de documents scientifiques de niveau recherche, publiés ou non, émanant des établissements d'enseignement et de recherche français ou étrangers, des laboratoires publics ou privés. 


\section{On the Damage Criteria and their Critical Values for Flowforming of ELI Grade Ti64}

Conference Paper in Key Engineering Materials · September 2014

DOI: 10.4028/www.scientific.net/KEM.622-623.1221

CITATION

1

2 authors, including:

\section{Dorian Depriester}

Ecole Nationale Supérieure d'Arts et Métiers

7 PUBLICATIONS 18 CITATIONS

SEE PROFILE
READS

49

Some of the authors of this publication are also working on these related projects: 


\title{
On the damage criteria and their critical values for flowforming of ELI grade Ti64
}

\author{
Dorian Depriester $^{1, \mathrm{a}}$, and Elisabeth Massoni ${ }^{1, \mathrm{~b}}$ \\ MINES ParisTech, Centre de Mise en Forme des matériaux (CEMEF), 1 rue Claude Daunesse CS \\ 10207, France \\ adorian.depriester@mines-paristech.fr, belisabeth.massoni@mines-paristech.fr
}

Keywords: Ti-6Al-4V, ELI grade, damage criterion, cold flowforming, fracture, processing parameters

\begin{abstract}
Cold flowforming is a chipless forming process that deforms tubular parts by reducing their outer diameter and thickness while increasing their length. It consists of a rotating mandrel and one or more rollers that are translated along the tube axis, thus plastically deforming it. Flowforming of Ti-6Al-4V (also known as Ti64) is of great interest for improving the mechanical properties of the material, such as yield stress and fatigue strength. However this alloy is known to have poor ductility at room temperature. Therefore, flowforming of Ti64 without failure or crack is a great challenge. In this present paper, the authors have attempted to predict the different failure modes occurring during flowforming. An experimental machine has been built at the Center for Material Forming (CEMEF) in order to monitor the force on the single roller, the torque on the mandrel and the actual rotation speed of the roller as well. Numerous flowforming tests have been performed using different processing parameters, such as working depth, roller feed and initial geometry, in order to investigate the critical values which lead to the failure of the flowformed tube. In addition, numerical simulations of the process have been performed using the FORGE FEM solver. The results of the simulations have been used to evaluate the relevance of usual failure criteria (Crockford-Latham, Rice-Tracey and Oyane).
\end{abstract}

\section{Introduction}

Flowforming process. Flowforming (also called tube spinning) is a chipless production method to deform an initially tubular part, by reducing its wall thickness and then to elongate it. As depicted in figure 1, flowforming involves several idle rollers (usually three) which translate along the axis of the initial tube mounted on a mandrel. The mandrel is rotating with that tube while the rollers are progressively reducing the thickness of the tube. In so-called backward flowforming, the material elongates on the opposite direction from the roller feed, as white and black arrows indicate in figure 1.

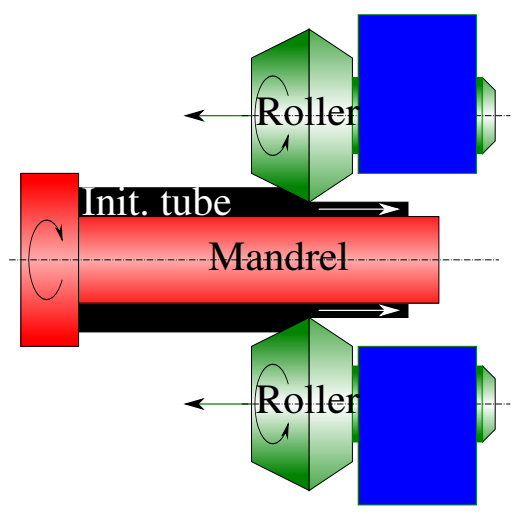

Fig. 1: Schematic view of the conventional flowforming process, involving two rollers. White arrows denote the tube elongation and black arrows denote the rollers feed.

While several materials are widely used for cold flowforming, such as aluminium alloys $[1,2]$ and low carbon steel $[3,4]$, a few authors $[5,6]$ have reported successful flowforming of Ti-6Al-4V 
alloy (also known as Ti64). In [5], authors have produced tubes utilizing different means ( $\beta$ extrusion, $\alpha-\beta$ extrusion, rotary piercing and flowforming) and extensively studied the mechanical properties of those tubes. They have concluded that the flowforming process was the best candidate to improve yield stress, ultimate tensile stress and fatigue properties together without any remarkable decrease in ductility. Those improvements are related to the grain refinement and the dynamic recovery/recrystallization phenomena occurring during flowforming $[5,6]$.

Failure criteria. The prediction of failure during flowforming is in great interest in order to predict the critical processing parameters. However, this prediction is still a great challenge because of the complex strain path undergone by the flowformed material. In [1], tube spinnability has been defined as the maximum thickness reduction reached by flowforming before failure. However, this definition takes neither the initial geometry (e.g. inner diameter) nor the processing parameters (e.g. feed rate and mandrel rotation speed) into account. Indeed, it has been shown that the final geometry highly depends on the processing parameters for flowforming [2]. As a result, different processing parameters would lead to different spinnability values.

In [7], authors have reported two types of defects occurring during flowforming of SAE 4130 steel tubes: the first is characterized by a long, sharp, longitudinal wall crack. This crack has been attributed to inclusion in the material, resulting in large stress concentrations around those particles. The second type of defects reported by the previous authors is internal circular cracks, occurring at the inner surface of the tube. This kind of cracks is really similar to the well-known central burst defect (also called chevron defect), reported in tube and rod drawing.

The aid of finite element method (FEM) can help to predict the failure, but it requires adequate failure criterion. It has been reported in [8] that the Crockcroft-Latham criterion [9] was really efficient for predicting the central burst defect during extrusion and wire drawing. Furthermore, in [10], authors have investigated the validity of both Latham-Crockcroft and Oyane's [11] criteria using different mechanical tests, they have concluded that both the aforementioned criteria successfully estimated free-surface cracking as well as internal cracking.

Objectives. The objectives of this work are to investigate the critical flowforming parameters which lead to higher elongation of the tube without cracks nor failures of the material and to evaluate and the ability of some damage criteria to predict the risk of failure during flowforming. In this paper, the normalized Crockcroft-Latham criterion, the Oyane's criterion and the Rice and Tracey's criterion [12] will be investigated. The damage criteria used in this work are defined as bellow:

$$
\begin{aligned}
\text { Crockcroft-Latham (normalized) [9]: } & \mathrm{D}_{\mathrm{CL}}=\int_{0}^{\bar{\varepsilon}} \frac{\sigma_{1}}{\bar{\sigma}} d \bar{\varepsilon} \\
\text { Oyane [11]: } & \mathrm{D}_{\mathrm{Oy}}=\int_{0}^{\bar{\varepsilon}}\left(1+\mathrm{A} \frac{\sigma_{H}}{\bar{\sigma}}\right) d \bar{\varepsilon} \\
\text { Rice and Tracey [12]: } & \mathrm{D}_{\mathrm{RT}}=\int_{0}^{\bar{\varepsilon}} \frac{1}{1.65} \exp \left(\frac{3 \sigma_{H}}{2 \bar{\sigma}}\right) d \bar{\varepsilon}
\end{aligned}
$$

In the previous equations, $\sigma_{1}, \sigma_{H}$ and $\bar{\sigma}$ denote the maximum tensile stress, the hydrostatic pressure and the Von Mises equivalent stress, respectively. $\bar{\varepsilon}$ denotes the equivalent plastic strain.

Experimental. Industrial flowforming machines usually involve three (or more) rollers in order to improve productivity and prevent the mandrel from bending due to forming loads. However in this study, flowforming using only one roller will be investigated.

An experimental flowforming machine has been built at the CEMEF. It mainly consists in a working idle roller, mounted on force sensors, and a mandrel equipped with torque sensor. The experimental set-up is illustrated in figure 2. Due to absence of opposite roller, the bending of the mandrel 
has been avoided thanks to the so-called follow rest, which consists of two additional idle rollers in contact with the mandrel. In addition, since the roller is idle, a tachometer has been implemented on its axis in order to monitor its actual rotation speed.

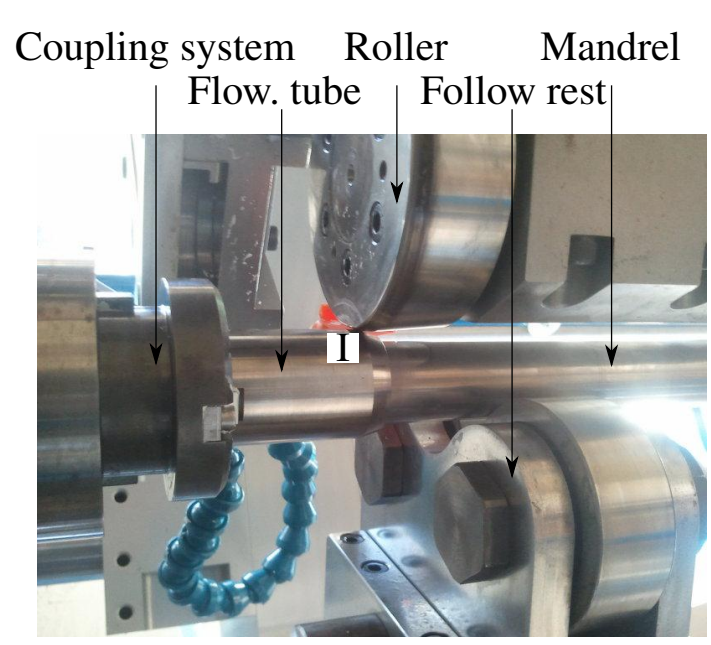

(a) Front view

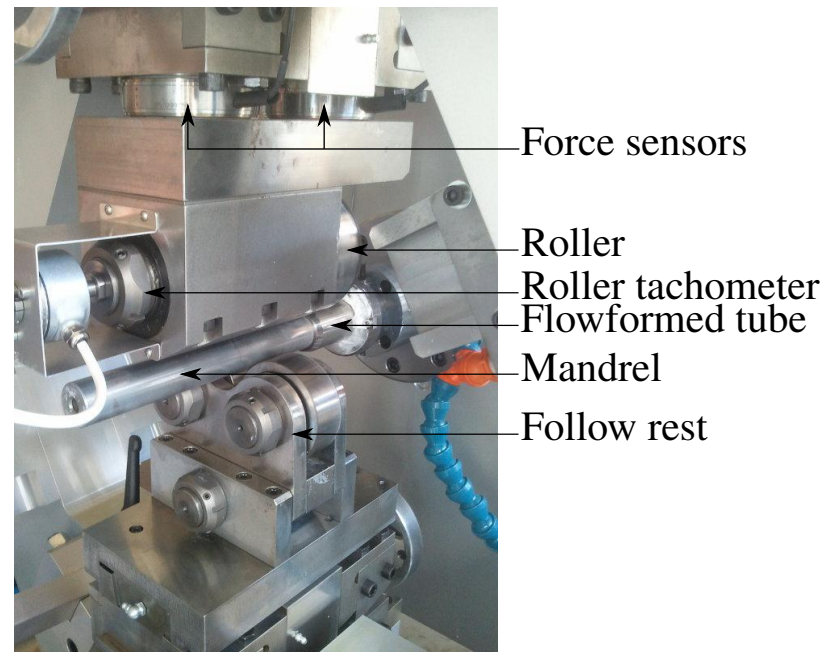

(b) Back view

Fig. 2: Photographs of the experimental set-up

\section{Experiment}

Processing parameters. Several flowforming tests have been performed on Extra Low Interstitial (ELI) grade Ti64, using different processing parameters such as working depth $\left(W_{d}\right)$ and feed by revolution $(f)$. Furthermore, two different values of the initial wall thickness have been investigated: $2.5 \mathrm{~mm}$ (referred as thin geometry bellow) and $5 \mathrm{~mm}$ (referred as thick geometry bellow). All tests have been conducted till fracture. For confidential purpose, let $f=f_{\text {ref }}$ be the reference value of the feed-by-revolution. In this paper, the investigated values of $f$ will be equal to $f_{\text {ref }}$ or to twice its value.

It is worth mentioning that despite the presence of the follow rest beneath the mandrel, high loads on tools $(30 \mathrm{kN}$ to $60 \mathrm{kN})$ lead to substantial discrepancies between the programmed working depth and the actual one. As a result, all values of the working depth given in this present paper have been calculated from the geometries resulting from each flowforming pass.

Numerical simulation. FEM simulations of the flowforming operations have been computed using the FORGE 3 software. In order to reduce the computation time, the proper rotation speed of the roller on its axis (experimentally recorded thanks to the tachometer) have been directly used as a kinematic condition of the roller during the simulations. As a result, each simulation of flowforming pass have lasted between $80 \mathrm{~h}$ to $400 \mathrm{~h}$ using $32 \mathrm{CPUs}$.

\section{Results}

Maximum thickness reduction. Results of the different flowforming operations are summarized in table 1. In this table, the last value of each column is the attended wall thickness reduction of the tube, leading to failure of the corresponding specimen. The feed rate as well as the initial geometry of each specimen are also given in this table. Specimen 1 (thin geometry, low feed rate) has failed at the $2^{\text {nd }}$ pass; specimen 2 (thin geometry, low feed rate) has failed at the $1^{\text {st }}$ pass; specimen 3 (thin geometry, high feed rate) has failed at the $6^{\text {th }}$ pass and specimens 4 (thick geometry, low feed rate) and 5 (thick geometry, high feed rate) have failed at the $3^{\text {rd }}$ pass.

Fracture patterns. During flowforming, two different fracture patterns have been evidenced: 
Table 1: Thickness reduction ratio of each specimen at the different flowforming passes, depending on the initial geometry and the feed-by-revolution.

\begin{tabular}{|c|c|c|c|c|c|}
\hline & \multicolumn{5}{|c|}{ Specimen ID } \\
\hline & $f=f_{\mathrm{ref}}$ & $f=f_{\text {ref }}$ & $\begin{array}{c}3 \\
f=2 \cdot f_{\mathrm{ref}}\end{array}$ & $\begin{array}{c}4 \\
f=f_{\text {ref }}\end{array}$ & $\begin{array}{c}5 \\
f=2 . f_{\text {ref }}\end{array}$ \\
\hline Geometry & Thin & Thin & Thin & Thick & Thick \\
\hline $1^{\text {st }}$ pass & 0.44 & 0.48 & 0.28 & 0.18 & 0.18 \\
\hline $2^{\text {nd }}$ pass & 0.60 & & 0.40 & 0.30 & 0.30 \\
\hline $3^{\text {rd }}$ pass & & & 0.52 & 0.58 & 0.54 \\
\hline $4^{\text {th }}$ pass & & & 0.64 & & \\
\hline $5^{\text {th }}$ pass & & & 0.76 & & \\
\hline $6^{\text {th }}$ pass & & & 0.80 & & \\
\hline
\end{tabular}

- long longitudinal cracks, as depicted in figure 3a. Those cracks can appear multiple times on the same specimen (up to 12 times)

- circular cutout, as depicted in figure $3 b$

Only the specimen 3 have failed according to the second pattern. Considering the low thickness (about $0.3 \mathrm{~mm}$ ), this cutout may be attributed to a chevron-like crack, growing through the whole thickness. Those results are similar to that reported in [7].

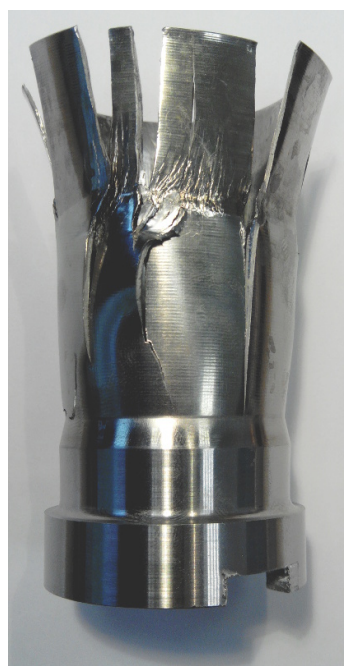

(a) Longitudinal burst

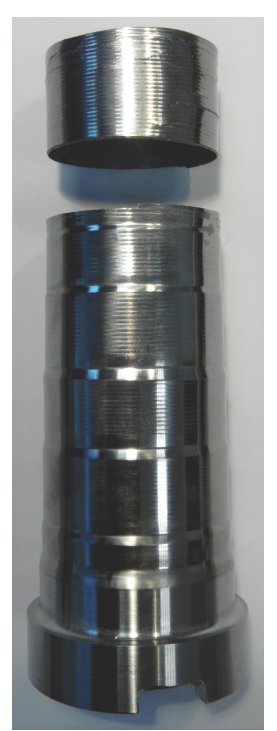

(b) Circular cutout

Fig. 3: Typical fracture patterns resulting from flowforming. Photograph (a) shows specimen 1, and Photograph (b) shows specimen 3.

Macroscopic elongation. Neglecting the shear strain, one can consider the change in cross section to evaluate the true longitudinal elongation introduced by flowforming (denoted $e$ hereafter), as defined bellow:

$$
e=-\log \left(\frac{S}{S_{0}}\right)=-\log \left(\frac{R_{\mathrm{ext}}^{2}-R_{\mathrm{int}}^{0}{ }^{2}}{R_{\mathrm{ext}}^{2}-{R_{\mathrm{int}}{ }^{2}}^{2}}\right)
$$

$S_{0}$ and $S$ being the initial and the resulting cross-sections, respectively. $R_{\text {int }}^{0}, R_{\text {ext }}^{0}, R_{\text {int }}$ and $R_{\text {ext }}$ denote the initial inner, the initial outer, the resulting inner and the resulting outer tube radii, respectively. For 
each single specimen, let $e_{s}$ be the maximum macroscopic elongation without failure (i.e. at the last successful pass). By contrast, let $e_{f}$ be the attended macroscopic elongation at failure (i.e. at the pass leading to failure). The corresponding values are given in table 2. As a result, at a given experimental configuration, $e_{s}$ and $e_{f}$ respectively give the lower and the upper bounds for the maximum elongation $\left(e_{\max }\right)$.

Table 2: Lower and upper bounds for the critical values of the elongation $\left(e_{\max }\right)$ as well as investigated damage parameters.

\begin{tabular}{|c|c|c|c|c|c|c|c|c|}
\hline \multirow[t]{2}{*}{ Specimen ID } & \multicolumn{4}{|c|}{ Before failure } & \multicolumn{4}{|c|}{ At failure } \\
\hline & $e_{s}$ & $\mathrm{D}_{\mathrm{CL}}$ & $\mathrm{D}_{\mathrm{Oy}}$ & $\mathrm{D}_{\mathrm{RT}}$ & $e_{f}$ & $\mathrm{D}_{\mathrm{CL}}$ & $\mathrm{D}_{\mathrm{Oy}}$ & $\mathrm{D}_{\mathrm{RT}}$ \\
\hline 1 & 0.27 & 0.67 & 0.87 & 0.22 & 0.42 & 1.05 & 2.16 & 0.50 \\
\hline 2 & 0 & 0 & 0 & 0 & 0.30 & 0.78 & 0.98 & 0.24 \\
\hline 3 & 0.38 & $>0.51$ & $>0.66$ & $>0.17$ & 0.52 & & & \\
\hline 4 & 0.16 & 0.51 & 1.04 & 0.25 & 0.38 & & & \\
\hline 5 & 0.15 & 0.44 & 0.76 & 0.18 & 0.33 & 0.90 & 1.55 & 0.37 \\
\hline
\end{tabular}

Numerical simulations. Efforts have been made to simulate the different processing schemes, with respect to the processing parameter given in table 1 . Nevertheless, considering the required time for the computation of each pass (from $80 \mathrm{~h}$ to $400 \mathrm{~h}$ ), only the following flowforming operations have been simulated:

- specimen 1: till fracture (2 passes)

- specimen 2: till fracture (1 pass)

- specimen 3: first and second pass only

- specimen 4: first and second pass only

- specimen 5: till fracture (3 passes)

The experimental data from the torque sensor on the mandrel and the force sensor on the roller have been compared to the simulated loads in order to ensure that the constitutive laws used for the simulation was in good agreement with the experimental conditions. Thanks to numerical simulations, the damage parameters introduced above have been computed. The results in terms of equivalent strain as well as damage parameters of specimen 2 are given in figure 4.

Numerical simulations have shown that the material undergoes very large strain $(>3)$ during flowforming. Furthermore, a strain gradient along the tube axis has been evidenced, as depicted in figure 4a. This gradient is due to the pile-up effect as well as the buffering capacity of the thin geometry: at the beginning of the flowforming pass, the tube undergoes elastic strain due to compressive stresses parallel to its axis. While the roller moves forward, the remaining length upstream from it reduces, thus its ability to elastically absorb deformation reduces.

Figure $4 \mathrm{~b}, 4 \mathrm{c}$ and $4 \mathrm{~d}$ show the damages distributions. It is worth noticing that the three considered damage parameters are roughly consistent with each other: the most damaged elements are located at the inner surface of the tube, and the damage increases with the distance from the tube tip. The largest value of any damage parameter corresponding to the last successful flowforming pass of each specimen gives a lower bound of the critical value of this parameter. On the opposite, its value when failure is evidenced gives the upper bound of this parameter. As a result, the lower and the upper bounds of the damage parameters evidenced by numerical simulations are given in table 2 .

Near the tube end, the equivalent strain (and the damage parameters as well) appears to be quite low. This undeformed part is due to the cone machined on the initial tube in order to avoid the tube from buckling at the beginning of the flowforming passes. 

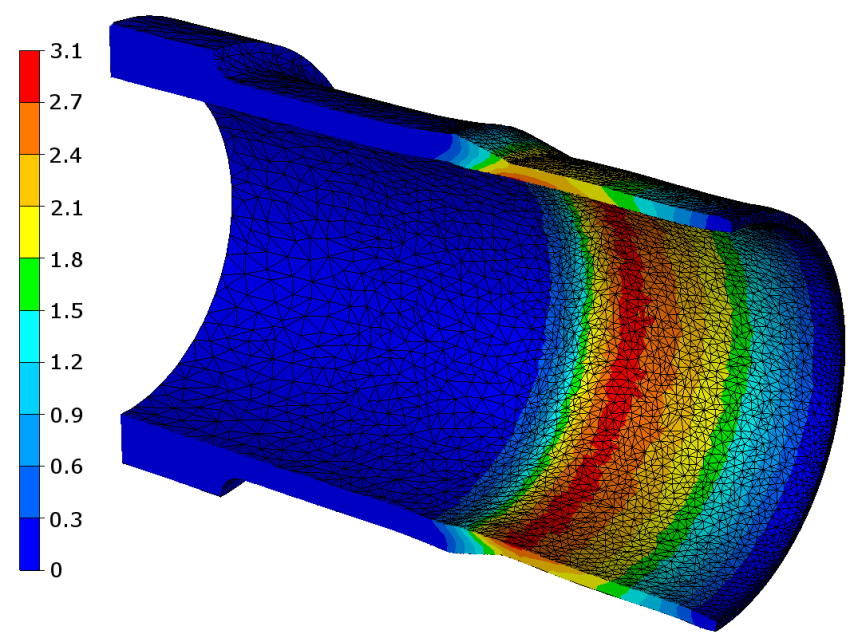

(a) Equivalent strain
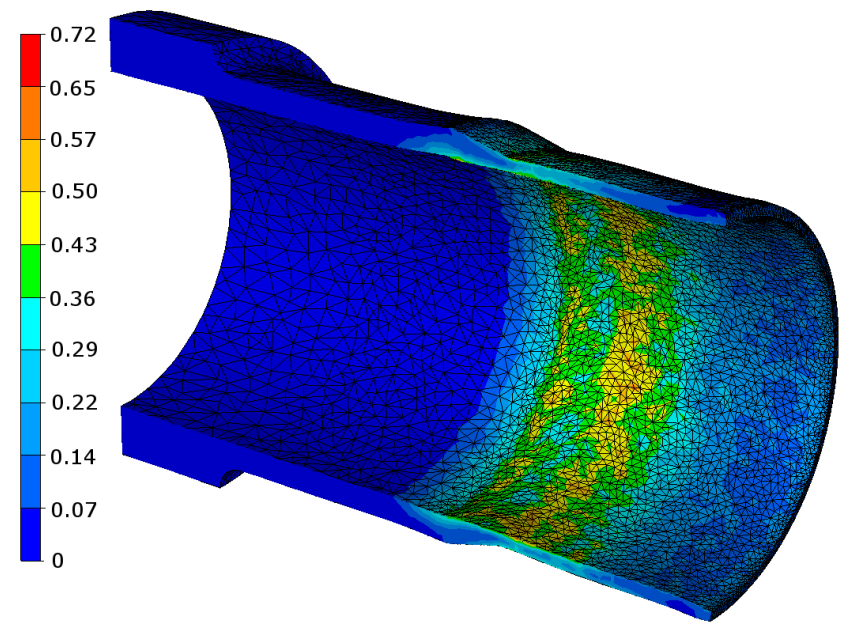

(c) Oyane's parameter
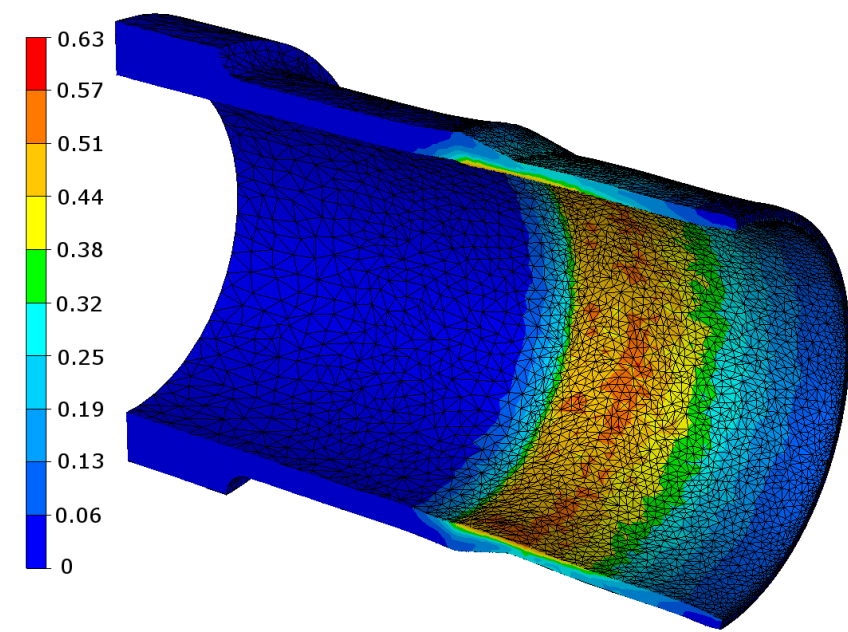

(b) Latham and Cockroft's parameter

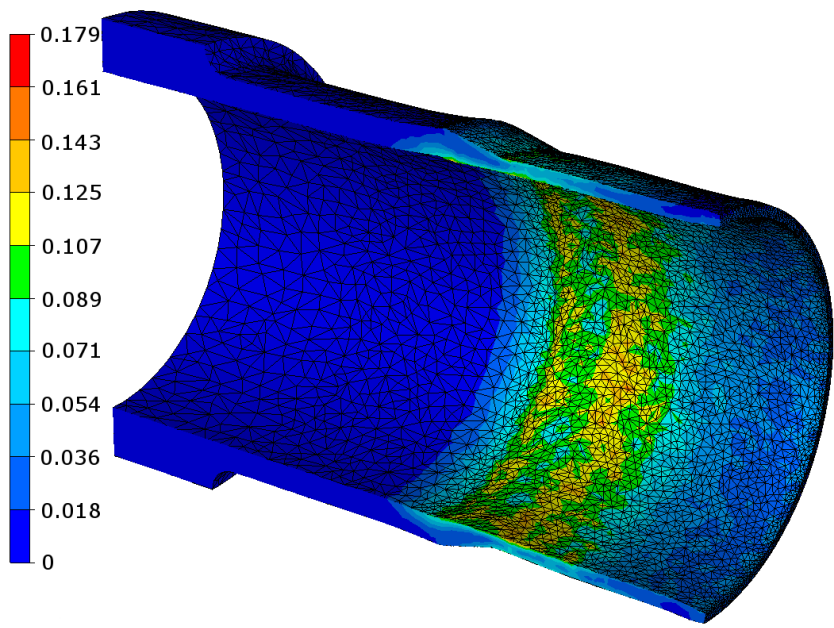

(d) Rice and Tracey's parameter

Fig. 4: Numerical results: flowforming of specimen 2 in terms of equivalent strain (a) and damage parameters (b-d). Results are given when failure has been evidenced.

\section{Discussion}

Specimen 1 and 2 are based on the same initial geometry and the same tool kinematic $\left(f=f_{\text {ref }}\right)$, furthermore the corresponding values of $e_{s}$ and $e_{f}$ are consistent with each other. Thus, for that experimental set, it appears that $0.27<e_{\max }<0.30$. On the contrary, according to the specimen 3 , an increase on the feed rate substantially increases the value of $e_{\max }: 0.38<e_{\max }<0.52$. Conversely, for the thick geometry, the feed rate appears to have little influence on the critical elongation: $0.16<e_{\max }<0.33$. Those results show that the tube spinnability, as defined in [1], depends on both the processing parameters and the initial geometry.

According to specimen 4, the lower bounds of the critical values for Oyane's and Rice and Tracey's damage parameters are 1.04 and 0.25 , respectively. Nevertheless, failure has been evidenced on specimen 2 at $\mathrm{D}_{\mathrm{Oy}}=0.98$ and $\mathrm{D}_{\mathrm{RT}}=0.24$. As a result, the Oyane's and the Rice and Tracey's damage criteria appear not to be relevant. On the contrary, all bounds for the critical value of the LathamCockroft parameter seem to be consistent with each other and to be comprised between 0.67 and 0.78. Those values are much higher than that usually reported in literature (e.g. 0.3 in [13]). When comparing damages values in specimen 3 and 5 (with $f=2 . f_{\text {ref }}$ ) with that of the other specimens (with $f=f_{\text {ref }}$ ), it appears to the higher the feed rate, the lower the damage values. 


\section{Conclusion}

Several flowforming tests have been performed on Ti-6Al-4V tubes, using different processing parameters as well as different geometries for the starting tube. In addition, numerical simulations have been performed in order to evaluate the ability of some damage criteria to foresee the critical processing conditions.

It has been evidenced that the higher the feed-by-revolution is, the lower damage increases, leading to larger attainable reduction ratio. The Cockroft-Latham's damage criterion has appeared to be an efficient way to predict cracking during flowforming operations. Its unusually large critical value (between 0.68 and 0.78) may be due to the complex strain path and the high compressive stresses during deformation. The knowledge of this value may help to predict the critical flowforming cases, even using more complex tool kinematics (for instance for non-constant thicknesses) with the aid of FEM simulations.

\section{Acknowledgement}

This work was made as part of the FLUOTI project, subsidized by the french National Research Agency (Agence Nationale pour la Recherche - ANR).

\section{References}

[1] Chang, S.-C., Huang, C.-A., Yu, S.-Y., Chang, Y., Han, W.-C., Shieh, T.-S., Chung, H.-C., Yao, H.-T., Shyu, G.-D., Hou, H.-Y., Wang, C.-C., and Wang, W.-S. (1998) Journal of Materials Processing Technology 80-81(0), 676-682.

[2] Davidson, M. J., Balasubramanian, K., and Tagore, G. (2008) Journal of Materials Processing Technology 200(1-3), 283-287.

[3] Roy, M., Klassen, R., and Wood, J. January 2009 Journal of Materials Processing Technology 209(2), 1018-1025.

[4] Haghshenas, M., Jhaver, M., Klassen, R., and Wood, J. (2011) Materials \& Design 32(6), 36293636.

[5] Gungor, M. N., Kramer, L. S., Ucok, I., Dong, H., and Tack, W. T. (2007) pp. 37-45.

[6] Depriester, D. and Massoni, E. (2013) Key Engineering Materials 554, 157-168.

[7] Rajan, K. M. and Narasimhan, K. October 2001 Practical Failure Analysis 1(5), 69-76.

[8] Ko, D.-C. and Kim, B.-M. (2000) Journal of Materials Processing Technology 102(1-3), 19-24.

[9] Cockcroft, M. and Latham, D. (1968) J Inst Metals 96(1), 33-39.

[10] Gouveia, B., Rodrigues, J., and Martins, P. (2000) Journal of Materials Processing Technology 101(13), $52-63$.

[11] Oyane, M. (1972) Bulletin of JSME 15(90), 1507-1513.

[12] Rice, J. R. and Tracey, D. M. (1969) Journal of the Mechanics and Physics of Solids 17(3), 201-217.

[13] Stefanik, A., Dyja, H., and Mróz, S. (2011). 